\title{
Gamma Rays, Q-Values, and Kerma Factors
}

\author{
by
}

\author{
D. W. Muir
}

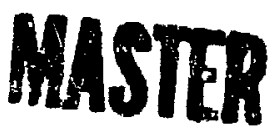

An Affirmative Action/Equal Opportunity Employer 
This work was supperted by the US Energy Reszarch and Developnent Administration. Division of Controlled Thernionus:lear Research.

Printed in the United States of Mmerica. Available from National Technical in fo:mation Service

U.S. Department of Commerce 5285 Por: Roy:ll Road Springficld, V 4,22151

Price: Printed Copy \$3.50 Microfiche \$2.25

Thin seport was prepared at an accoust of worky oponzored

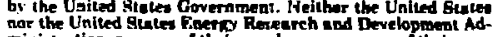
ministrution, hor any of their employeso. nor any of tbetr con tractors. ubcontractorn, of their employees. makes any

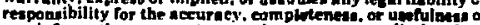
eny information. apparatus, product, or process disclowed, of represents that is we gould nat infitage privitely owned 
GAMMA RAYS, Q-VALUES, AND KERMA FACTORS

by

D. W. Mu1r

ABSTRACT

Formats have been proposed to allow the inclusion of e::aluated neutron kerma factors in ENDP/B. The task of preparing evaluated kerma factors is analyzed in this report and 18 found to present numerous difficultles. Two alternative approaches tu kerma-factor calculations are suggested, bnth of which require modiffcations of existing evaluations, notably through the Inclusion of cross sectlons now missing for a number of neutron reactions, to allow postevaluation kerma-factor processing. The ifrst approach requirea neutron-Induced sharged-particle spectra, in addition to the missing reaction data. The second approach, which would not require the charged-particle spectra, would enforce energy conservation in the computed results.

\section{INTRODUCTION}

In a number of angineering applications, thes has been Increasing need for the calculation of factors which convert neutron fluence to kerna (kinetic energy release in materials). The kerma factor cen be defined as the total neutron interaction cross section multiplied by the average value (per interaction) of the sum of the kinetic energles of the recoll nucleus and seccndary charged particles. The kerma factor is a one-dimensional array, simflar to a reaction crose section, and can be represented in fine detall on a continuous-energy basis or fluxaveraged over neutron energs multigroups.

The avallability of accurate kerma factors is Important in such diverse ereas as fusion reactor blanket design, blological dosimety, fast neutron radiation therapy, and nuclear weapons effects. Moist of these comments are direrted toward the problem of the calculation of neutron heating in fusion reartor blankets, but the needs of the other applications mentloned are cunstdered as vell. In most of these areas, the neutron fluence is calculated using multigroup techniques, so that multigrouped kerma factors would appear to be adequate in the near term. Another common feature of these application areas is an interest in high-energy (14 MeV) neutrons $z s$ well as low-energy neutrons. In contrast to the lower energy region, where the kerma factor 1s dow Inated by one or two (usually well-knowm) reactions, at $14 \mathrm{MeV}$, elastic scattering, Inelastic scattering, exothermic reactions, and endothermic resctions all contribute significantly to the $\mathrm{kl}$ netic energy rolease. This complexity has made the calculation of accurate kerma factors a problem of continuing Interest.

A number of computez programs ${ }^{1-3}$ have been written to calculate kerma factors. The most recent of these, MACK, ${ }^{1}$ processes the neutron f1les from ENDF/B (or data in the same format) for all reactions which result in the release of sigaificant atiounts of charged-particle energy. Like most of 1ts predecessora, MACK is a stand-alone program in that it can be operated independently of other nuclear data processing codes. This stand-alone feature, plus the previously mentioned complexity of kerma-factor calculations, has led to suggestions

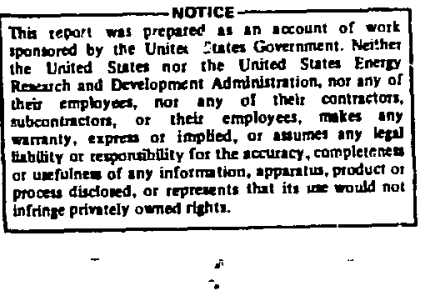


that MAC: be used as part of the ENDF evaluation process to produce evaluated pointwise kerma factors. These pointwise kerma-factor data would be encered Into ENDF/B as primary data. Multigroup kerma factors could then be processed by the usual multigroup processing codes, fust as they process neutron reaction cross sections, during the process of producing neutron transier matrices. Th1s proposal has 1 ts merits, but as will be shown, it mignt cause more problems than it would solve.

\section{KERMA-FACTOR COMPLICATIONS}

To analyze the motivatior behind the proposal to produce evaluated kerma factore, we describe below several sources of complexity in the calculation of kerma factors from ENDF/B basic data.

\section{A. Mlosing Reaction Cross Sectiors}

Meny reaction cross sections, such as $\sigma_{n, p}$ and $\sigma_{n, \alpha}$, are missing fo: the heavier materials. This is important because, in the Fe-Mo region, $(n, p)$ and $(n, a)$ reactions are responsible for about $70 x$ of the cotal neutron heating. 1

B. Irc ompletely Described Gamma-Ray Events Gamma-ray production events are of ten incompletely described. For example, in the $\left(n, n^{\prime} p y\right)$ reaction, one must calculate the average energy released in the form of aecondary neutrons and photons In order to calculate the kerma (froton plus recol] nucleus) by energy balance. If the photon corresponds to discrete level decay, the level can be indexed in the neutron file. Usually this level information $l_{s}$ missing, and if the gamma-ray spectrum Is a continuum, then there is not even a format for giving the spectrum in the neutron file. Alternatively, one could process the proton spectrum (which 1s formatced, but presently there is no proton spectral data in the files). A similar difficulty arises in $(n, 2 n y)$ events, Unless one knows the average energy of each neutron, one cannot calculate the recoll energy without approximation.

\section{Computations from Beta Decay}

The total energy deposition in a given material of ten Includes a olgnificant contribution from the beta decay of neutron-reaction products. In principle, one could calculate this decay heat using calculated neutron fluxes and a speclal-purpose decay heat code such as CINDER, ${ }^{4}$ but in CTR froblens there has been a trend toward Including the decay heat in the kerme factor. The calculation of these "delayed-kerma" factors requires input data which are not included in the ENDF neutron and ganma-ray formats and files.

We now turn to a discussion of the problem areas listed above.

\section{MISSING REACTION DATA}

In the production of evaluated poincwise kerma factors, the problem of ralssing data could be handled by preparing a speclal-purpose library of modelgenerated reaction cross sections, When an 1mportant reaction is missing from a given ENDF evaluation, MACK could acceso this library to get the information needed to produce a senstble kerma factor.

The fact that some 1mportant cross sections have not been measured is not a strong argument for the production of evaluated kerma factors. It would seem preferable to add any new model-generated data for the $(n, p)$ and $(n, \alpha)$ cross sections directiy into the ENDF/R files as raptdly as possible, and then to run MACK (or a similar code) after the files have been updated. In this way, future revistons of these estimated cross sections would require that the evaluator revise fust the cross sections in question and noc the evaluated kerma factur 28 weli. Th1s approach would be a reasonable altc native to the in-clusion of evaluated kerma directly in the ENDF/B f1les.

\section{GAMMA-RAY PRODUCTION PROBLEMS}

The same sort of comment irplies to the second difficulty mentioned above. If one uses model calculations to supply charged-particle energy spectra for the calculations of kerma factors, then those spectra should be inserted directly into the aprropriate ENDF/B files (the MT $\Rightarrow 700$ series, in this case) where they can be eastly inspected and revised whenevpr necessary. As in the case of the model-generated $(n, p)$ and $(n, \alpha)$ cross sections discussed above, there are 1wportant, applications, completely unrelated to kerma, which would benefit from the exfstence of evaluated neutron-1nduced chargedparticle energy spectra in ENDF/B. For example, at the temperatures generally encountered in astrophys1cs, proton and alpha-particle ranges are comparable to neutron ranges, so that charged-particle transport is required. 
It 1 possible that it will take several years to f1ll in the charged-particle opestrum f1les. In the meantime, ic 1s important to note that kerma factors can be calculated without a full description of the charged-particle spectra. One can do this by using the gama-ray production files where provided and using energy-balance relations. This approach, which offers a second alternative to putting kerms factors directly into the ENDF files, is developed In detall in the Appendix. It is vilnerable to two distinct obfections; namely. (1) MACK is presently not coded to handle the gamong ray production files, and (2) gama-ray production evaluartons do not exlat for many ENDF materiala.

In response to the first objection, we note that there exist ENDF processing codes (e.g., LAPHANO ${ }^{5}$ ) which can process the ENDF/B gamma-ray data Into a form autable for the use of energy-balarice rechniques. Our response to the secoad point 1s that conaiderable momentum is developing to 1mprove this situation. In ENDF/B-III only 11 evaluations contained gamma-ray production cross sections. In ENDF/B-IV, th1s w11 grow to about 35. Also, it should be noted that in neutzon-transport problems not involving fission (e.g.. flssion-reactor shield1ng, fuslon-reactor blankets, and a transport of weapons radiation) the gamm-ray heating 18 usually of the same order of magnitude as the direct neutron heating. Thus, there wll be relatively few cases were neutron-heatIng (kerma) calculations will be made in the absence of gamma-ray production and traneport calculations.

Just as In the MACK approach, the method outlined in the Appendix depends on the avallability of cross sectlons for all important non-elastic reactlons, such as $(n, p),(n, \alpha),\left(n, n^{\prime} p\right),(n, 2 n)$, etc. In contrast to the MACK approach, the energy-balance method makes it possible for all reactions to be treated without approximation even if the angle and energy distrioutions of the charged-particle products are unaval lable.

\section{DELAYED KERMA FROM DECAY PROCESSES}

For some nuclides and in some neut,ron energy regions, the kerma factor 18 dominated by particle em1ss:on (betas, alphas, conversion electrons, etc.) from neutron activation products. M. Abdou mentions 1 the striking example of ${ }^{7} \mathrm{~L} 1$. At low energies the majer energy-release wechalism is radlative sapture, followed by rapld beta and alpha decaya:

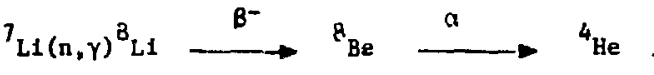

$$
\begin{aligned}
& t_{1 / 2}=0.8 \theta \quad t_{1 / 2}=\text { short }
\end{aligned}
$$

The charged-parficle energy released in the betr and alpha decays $189.31 \mathrm{MeV}$, wh1le the capture gamas ray accounts for oniy $2.03 \mathrm{MeV}$. This strong domInance of decay heating over prompt (prior to betadecay) heating is quite unusual in CTR neutronics calculations, but it foes point up the fact that decay heating must be treated in some fashion, even if It is approximate. The information needed to assess decay heating is not contalned in the present ENDF neutron and gama formats and flles. Further, the decay modes of activation projucte are widely varled. Thus, it appears that decay-heating data should be entered in the files by the evaluator.

Probably the most direct way to enter the dtscyheating Information is to flag the contributing neutron reactions and to enter the corresponding data in a separate flle. For example, In the $7_{\mathrm{L} 1}$ example glvall above, the capture cross section MF = 102 could be flagged to Indicate the existence of algnificant decay-heating processes. At least three pisces of data would then be entered elsewhere in the neutron file. One would like to have (1) the characterlotic decay time ( 0.8 seconds, in this example); the average amount of delayed kerma per capture (9.31 MeV here); and (3) the average amount of delayed gamma-ray energy release per capture $(* 0 \mathrm{MeV}$ here). If more than one activity is zroduced, resulting in a nonexponential decay-heat deposition rate, several of these three-number data sets could be entered for a given inftiating reaction. The initial data for this short delayed-kerme file probably would be gathered in a rather ad hoc fashion. Eventually, however, one would expect an automated IInk between this file and the extenalve ENDF/B decay-heating file now being formatted. 6

\section{vI. STLMARY}

We have examined three major reascuss for adoptIng the proposal to include evaluated pointulise kerma factors in the EDF neitron file. AJ.1 three reasons can be reduced to the statenent that the evaluated data in ENDF/B is Inadequat for the calculation of accurate kerma factors. We feel that the 
solution to this problem is to evaluate and add new differential data, wherever this is necensary to permit pustevaluation kerma-factor processing. This will require revisiong of many existing ENDF evaluations to Include mode $\downarrow$-generated estimates of certain cross sections, as well as a format change to accomnodate the delayed-kerma data.

In addition, if one chooges to produce kerma factors using only the neutron flles using MACK (the f1rst alternative), then one also needs cvaluated charged-particle spectra for certain reactions. If one chooses to use both the neutron and gamma-ray files and energy-balance techniques (the second alternative), then the charged-part1cle apectra are not required for kerma calculations.

In either case coneiderabie work will bave to be done on the ENDF files to allow meaningful postavaluation kerme calculations. It 1s felt, however, that this extra work is less than would be required under the original proposal to put evaluated kerma factors directly into the files. This conclusion 1s tased on the following congiderations: (1) the new microgcopic data w1l be encered in the Files explicitly making it easier to reevaluate and reviae the data in the future; (2) the evaluator w11 not be burdened with the task of understanding and operating a complex kerma-factor processirg code. In addition, the new microgcoplc data will be useful In orher applications such as activation and transmutation. An advantage reatrk'sed to the energybalance approach 18 that the calculated kecma fac- tors w11l be consistent (from an energy conservation viewpoint) with the evaluated neutron and gamma-ray f11es.

\section{ACKNOWLEDGHENTS}

The author would ike to acl nuwledge numerous helpful discussions of this problem with $M$. A. Abdou, L. Stewart, C. R. Welsbin, R. J. Labauve, D. R. Harris, and T. R. England.

\section{REFERENCES}

1. M. A. Abdou, C. W. Maynard, and R. Q. Hright, "MACK: A Program to Calculate Neutron Energy Release Parameters (Fluence-to-Kerma Factors) and Multigroup Reaction Cross Sections from Nuclear Data 1r. ENDF Format," Dak Ridge National Laboratory report ORNL-TM-3993 (1973).

2. J. J. Ritts, M. Solomito, and D. Stelner, "Kerma Factors and Secondary Gamme Sources for Some Elements of Interest in Thermonu :lear Blanket Assembl1es," Oak RIdge National Laboratory report ORNL-IM-2564 (1970).

3. R. L. Bach and R. S. Caswell, "Energy Transfer to Matter by Neutrons," Radiation Research 35 , 1. (1968).

4. T. R. England, "Ari Investigation of Fission Product Behavior and Decay Heating in Nuclear Reactors," Trans. Am. Nucl, Soc. 15, 443 (1972).

5. D. J. Dudzlak, R. E. Seamon, and D. V. Sus.o, "LAPHANO: A Po Multigroup Photon-Production Matrix and Source Code for ENDF," Los Alamos Scientific Laboratory report LA-4750-MS (INDF156) (1972).

6. R. E. Sshenter, "Fission Product Subcomittee Report," an enciosure in "Sumnary of CSEWG Heet1ng of May 23-24, 1973," Brookhaven National Laboratory memorandum.

\section{APPENDIX}

THE ENERGY-BALANCE APPROACH

Neutron downscatter, gamma-ray production, and charged-particle energy release (kerma) are intimately related through the law of conservation of energy. The ENDF system 1s now committed to the gual of developing valid cross sect.tons for the first two procesnes, so it 1s only natural to consider the use of energy-balance techniques to derive kerma factorg from the exlsting neutron and gamma data.

In the following we denote by $\sigma_{1}$ (E) the cross section for a reaction of cype 1 induced by a neu- tron having energy $E$. The average value of the sum of the kinetfc energfes of the recoll nucleus and secondary charged particles we shall label $\mathrm{C}_{1}$. The avergge value of the sum of the energies of secondary neutrons will be labeled $N_{1}$ and the analogous quantity for gamma rays, $G_{1}$." is 18 sssumed to include the contributions froin ling-lived gamra-emitting 1somers. If an isomeric reaction product de-

* $\sigma_{1}, C_{1}, N_{1}$, and $G_{1}$ are atl functions of the neutron energy $E$. Unless needed for clartity, we will henceforth drop the functional notation. 
cays hy beta enisston, then production of that 1soner is treated as a different reaction type 1 from the reaction to the ground state. Heat generation due to beta decay itself is considered separately (see Sec. $v$ in the matn text).

Under the ground rules set down above, $Q_{1}$, the "ground-state" Q-value of reaction type 1 sacisfles the relation

$$
Q_{1}=\left(N_{1}+G_{1}+C_{1}\right)-E
$$

The karma factor $k_{1}$ for this reaction is defined as

$$
k_{1}=\sigma_{1} \cdot c_{1}
$$

and the total kerma factor $K$ is obtained by summing ove: all possible reactions.

$$
k=\sum_{1} k_{1}
$$

Combining Eqs. (1)-(3) we have the basic energybalance relation for kerma factci calculations,

$$
K=\sigma_{\operatorname{tot}} E+\left(\Sigma_{1} \sigma_{1} Q_{1}\right)-\left(\Sigma_{1} \sigma_{1} N_{1}\right)-\left(\Sigma_{1} \sigma_{1} G_{1}\right)
$$

where $\sigma_{\text {tot }}$ to the usual total neutron cross section. All four of the terms on the right hand s:de of Eq.

(4) can be computed fairly easily in a multigroup environment using the present ENDF neutron and gamma-ray processors at the same tine as the multigroup transfer matrices are prepared. Should a standard ENDF continuous-energy gamina-ray production processor be developed in the future, only a modest extenston of the continuous-energy neutron processors would be required to produce continuous-energy kerma factors using the energy-balance approach.

To clarify what we mean by ground state Qvalue, $Q_{1}$, we consider sone concrete exanples. $Q_{1}$ for both elastic and purely $\left(n, n^{\prime} \gamma\right)$ inelastic scattering is zero. Further, the $Q_{1}^{\prime} g$ for $\left(n, p_{0}\right)$, $\left(n, p_{1}\right), \ldots\left(n, p_{k}\right) \ldots$ wizere the subscript indicates the exclted state of the recoll nucleus, are all the sama. "Thus, to evaluate the Q-value term In Eq. (4) whet is needed is the "total" cross section for all Important nonscattering reactions. By "total" here we mean the sum over all states of excltation of the residual nucleus. For example,

$$
\left(\sigma_{n, p}\right)_{\text {total }}=\sigma_{n, p_{0}}+\sigma_{n, p_{i}}+\ldots+\sigma_{n, p_{k}}+\ldots .
$$

The reaction $\left(n, p_{k}\right)$ here does not include the reaction in which lêvel $\mathrm{k}$ decays by neutron siminission, ior example. That proce.'s is assumed to be included in the $\left(n, n^{\prime} p\right)$ cross section.
These cross gectiuns are the usual reaction cross sections included tn the ENDF/B files. Some of the more Important zeactions are Ifsted In Table I along

\begin{tabular}{|c|c|c|c|}
\hline MT & Reaction & $\mathrm{MT}$ & Reaction \\
\hline 16 & $(n, 2 n)$ & 102 & $(n, \gamma)$ \\
\hline 22 & $\left(n \ldots n^{\prime} a\right)$ & 103 & $(n, p)$ \\
\hline 24 & $(n, 2 n a)$ & 1.04 & $(n, d)$ \\
\hline $2 B$ & $\left(n, n^{\prime} p\right)$ & 107 & $(n, a)$ \\
\hline
\end{tabular}
with the assigned ENDF/b MT number.

TABLE I

SOME IMPORTANT NONSCATTERING REACTIONS IN ENDF/B

It has been noted earlier that these reaction cross sectlons are of ten missing in ENDF/B especlally for the heavier nuclides. We feel that this situation should be remedied as rapidly as possible through the use of nuclear model calculations where necessary. These cross sections are important not only for kerma-factor calculations, but also for transmutation and activation calculations. In fact, these total reaction cross sections are just what one normally measures in an activation cross section measurement.

A complication arises from the fact that the nuclear Q-value of a given reaction is isotope-dependent. If the raaction cross section is summed over 1sotopes, then the value of $Q_{1}$ which one should use in Eq. (4) depends on the fraction of the reactions due to each 1sotope, that is: $Q_{1}$ becomes a function of $E$. As long as the reaction cross sections are separated by 1sotope, however, $Q_{1}$ is a single number, which is alieady formatted for the ENDF/B reactions given in Table I. (In order to make the energy-balance approach meaningful, however, these Q-values need to be carefully reviewed for accuracy and consistency.) For obvious reașons, transmutation and activarion calculations also require the reaction data for Individual isotopes. Thus 1t appeara destrable to present the reaction data on an 1sotope-by-1sotope basls in future evaluations. For the present purposes, it does not appear necessary to fresent the neutron downscatter and gamma-ray production cress sections for individual 18otopes. If the neutron and gamma-ray data apply to a mixture of 1sotopes, then the $\sigma_{1}$ 1n Eq. (4) sirould be multiplied by the appropriate atom frac- 
tion and the sum on 1 extended over the number of isotopes present as well as over react:on types.

Is a general comment, it should be noted that the use of this energy-balance technique places new demands on the overall consistercy of the evaluated neutron and gamma-ray data. For example, if the energy spectrum of the secondary neucrons or gamas Is too hard, then from Eq. (4) lie see that the calculated kerma factor could very well become negative. We do not feel that this sizuation 19 neces- aarily Lndestrable. For one thing, this kind of calculation will raptdly point out areas where the. neutron and gamma-ray flles are unrealigtlc. Prior to the revision of the unrealistic neutron and/or gamma-ray data, the use of a kerma factor which enforces energy conserration would appear to be prefer: able to using one which is mre reasonable standing alone, but which 19 inconsigtent with the neutron and gamma-ray hata. 